\begin{tabular}{l|l|l} 
Tropelías. Revista de Teoría de la Literatura y Literatura Comparada, 18 (2012) & 3
\end{tabular}

Preliminar: Acción pública del poema

\title{
PRELIMINAR: ACCIÓN PÚBLICA DEL POEMA
}

Arturo CASAS

Grupo Alea de Análise Poética - Universidade de Santiago de Compostela

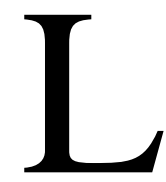

a multiplicación de las clases de prácticas poéticas en el mundo actual es un fenómeno notable que precisa aún de documentación rigurosa y de un análisis que esté a la altura de la complejidad de los hechos. Probablemente sea tarea aplazable la de detenerse a dictaminar si tales prácticas, en su enorme variedad, resultan ser en propiedad poéticas o si son ya otra cosa que no nos concierne -seamos nosotros la corporación que seamos. Sobre todo como consecuencia de su tendencia a explorar la interdiscursividad y la transmedialidad, a incorporar lo espectacular-presencial y de su mano la oralidad, a asociarse e hibridarse experimentalmente con prácticas de otra procedencia, pero sobre todo a fundamentarse y anunciarse justo desde ese lugar nuevo ${ }^{1}$ de lo mixto y lo intersticial, de lo indecoroso, por acudir a la entrañable pauta clasicista.

Lo cierto, de todos modos, es que el denominador poesía se hizo y se hace común a una proporción alta de las formas que vienen irrumpiendo por todas partes en el espacio público, desde la plaza al escenario y la taberna, desde el suplemento cultural al debate social y político. En ocasiones se aprecia un protagonismo destacado de la convergencia con la música o con lo escénico, otras veces irrumpen las artes espaciales y visuales, o directamente el vasto campo de la cibertextualidad. Sea cual sea la predisposición de base, es recurrente en todos estos usos la autoasignación poética como propia y matricial, también como anuncio o declaración de lo que será visto y/o escuchado. Sin duda, incluso, como etiqueta reclamada de legitimación: lo que hacemos es poesía.

Esto que se señala no resulta privativo de lo que algunas sensibilidades clasificarían como formas alternativas y secundarias del discurso poético. Antes bien, la poesía que hoy se publica como adscrita a patrones más o menos tradicionales, la sujeta a convenciones literarias y culturales firmes y duraderas, muestra también con

\footnotetext{
${ }^{1} \mathrm{O}$ no tanto. En realidad, podríamos estar ante otra querelle.
} 


\section{Arturo Casas}

frecuencia una necesidad de ampliación de su marco natural (el término es por completo equívoco, incluso errado): el texto se desteje, la voz se mixtifica, la función se olvida o intercambia. Ello ha supuesto desde luego toda una serie de descentramientos que vienen a cuestionar el lugar del poema, la entidad de la palabra poética como correlato de un cierto sujeto o de su subjetividad, lo distinto de la dicción y la referencia.

El signo de lo plural campea así a sus anchas en el poema. La consecuencia más perceptible parece que sea la quiebra -entiendo que necesaria- de la no tan vieja ecuación entre poesía y lírica. Corolario más que tangible de lo cual es la forma en la que el discurso poético ha dado en merodear los territorios diferenciales de lo dramático, lo narrativo y lo ensayístico. Contaminación y desnaturalización, pudiera pensarse desde algunos puntos de vista. En cualquier caso, el poema ha seguido con la modernidad caminos no disímiles de los seguidos por los otros grandes modos aludidos con los rótulos antedichos. ¿O no se reconoce legitimidad literaria a la novela lírica?, ¿al ensayo dialogado?, ¿al drama mediado por la voz de un narrador? Lo que parece evidente es que la intensidad y la pluralidad de las prácticas poéticas que exceden la esfera del poema lírico requieren del crítico y del analista cultural otra conceptualización, pudiera ser que otro oficio y otras competencias no clausurados en las inercias poetológicas. Seguramente por esto, son a menudo elaboraciones teóricas venidas de los límites del campo que reconocemos aún como estudios literarios, o llegadas desde fuera, las que más ágilmente retraman lo que aspiramos a conocer y lo que sobre ello se puede decir con el peso necesario.

De las coordenadas muy someramente descritas surgió en diferentes lugares, hace no tanto, un propósito claro: intentar saber algo sobre todas esas prácticas a la vez que se revisan los fundamentos y límites de los saberes disciplinarios prevalentes. En el caso de los grupos con los que colaboro, una de las claves que pareció más urgente atender fue precisamente la dimensión pública de la nueva poesía. Éste es, en efecto, el sustrato al que se vincula este dosier, razón por la que será oportuno indicar algo sobre el camino andado antes de pasar a lo que compete a unas páginas preliminares, no otra cosa que presentar adecuadamente el conjunto de artículos reunidos.

De lo que las investigaciones realizadas puedan representar hay dos líneas que destacaré. Una es el análisis crítico y comparado de la poesía gallega de los últimos cuarenta años, interesante como objeto de estudio no sólo por su propia pujanza y variedad sino además, en términos semiótico-culturales, por la secuencialidad temática, retórica, sociocultural y performativa de su recorrido histórico, con proyecciones culturales y políticas -adviértase que mucho más que imagológicas e identitariastambién relevantes, seguramente representativas de un cierto tipo de emergencia 
cultural. En este terreno deben situarse las investigaciones llevadas a efecto por el Grupo Alea de Análise Poética (GAAP), de la Universidade de Santiago de Compostela, preludiadas por una intensa dedicación previa del área de Teoría de la literatura y Literatura comparada de la misma institución a lo que cabe definir como una teoría enunciativa del poema. El carácter teórico-comparado de tales trabajos comparece de nuevo en el proyecto de investigación El discurso no lírico en la poesía contemporánea: Espacios, sujetos, hibridación enunciativa, medialidad, en el que participan investigadores de seis universidades y de diferentes departamentos. Entre ellos, Ben Bollig, Ana Chouciño, Cornelia Gräbner e Isaac Lourido, autores de otros tantos artículos en este dosier.

La segunda línea procede de los trabajos de Mieke Bal y la Amsterdam School for Cultural Analysis (ASCA), priorizadores de los conceptos (sobre los métodos) y de su comprensión como sedes provisionales de debate destinadas a establecer conciencia de las diferencias intersubjetivas y a plantear en ese plano tentativas de intercambio, según ha escrito la propia Bal en su clara y programática introducción al volumen Conceptos viajeros en las Humanidades (2009). Precisamente conceptos como los de resistencia cultural, performatividad y poesía no lírica, junto con otros varios de su misma constelación $^{2}$, han promovido una serie de iniciativas y de publicaciones que se concretarán ahora en sus capítulos de mayor relevancia.

Destaca la activación en 2007 de una red internacional de analistas y productores culturales y artísticos, Poetics of Resistance, en la que convergieron colaboradores procedentes de más de diez países coordinados por Cornelia Gräbner, profesora en Lancaster University y formada en ASCA, Ben Bollig (St Catherine's College, University of Oxford), William Rowe (Birkbeck College, University of London) y Arturo Casas (Universidade de Santiago de Compostela). Los resultados principales de la red se concentran en la celebración de dos encuentros científicos en Leeds y Santiago de Compostela y en tres publicaciones en las que, como es habitual en los planteamientos de la red, han participado también colaboradores externos. Los títulos son los siguientes: The Poetics of Resistance (Gräbner y Wood, 2010) ${ }^{3}$; Performing Poetry (Gräbner y Casas, 2011) ${ }^{4}$ y Resistance and Emancipation: Cultural and Poetic

\footnotetext{
${ }^{2}$ Véase al respecto Pollock (2007). Los conceptos tratados en esta publicación son: encuadre, agencialidad visual, espejo, trauma, life-mapping, pinchazo/punctum, historia, nostalgia, pedagogía, efficacity y compromiso.

${ }^{3}$ Cornelia Gräbner y David Wood seleccionan y exponen en su introducción un conjunto de conceptosguía de los trabajos del grupo. Además del par más obvio - resistencia y poesía/literatura/arte-, también los de autonomía, compromiso, estética, comunidad, nación, Estado, cosmopolitismo, revolución, modernidad, territorio y traducción (Gräbner y Wood, 2010: 1-19; acceso directo en http://www.cosmosandhistory.org/index.php/journal/article/view/208/307 [última consulta, 23-11-2011]). ${ }^{4}$ El índice del volumen figura en http://grupoalea.files.wordpress.com/2011/07/contents performingpoetry_2011.pdf [última consulta, 23-11-2011].
} 
6 Tropelías. Revista de Teoría de la Literatura y Literatura Comparada, 18 (2012) Arturo Casas

Practices (Casas y Bollig, 2011) ${ }^{5}$. Está próxima, por otra parte, la aparición del volumen Non-lyric Discourse in Contemporary Poetry (Baltrusch y Lourido, 2012), que recogerá las actas del congreso internacional homónimo celebrado en abril de 2011 en la Universidade de Vigo.

Permítaseme a continuación esquematizar alguna de mis propias posiciones sobre el asunto en el que aquí nos centramos. Figuran en una serie de publicaciones recientes, otras en curso, en algún caso mencionadas por los colaboradores del dosier. Juzgo que ofrecer previamente este esquema, aunque sea sin los necesarios matices y prescindiendo de la filiación de algunas claves, podría servir para la mejor comprensión de algunas referencias cruzadas:

1. El reajuste de la genericidad lírica antes del Romanticismo fue resultado de dos movimientos distintos pero coadyuvantes uno del otro: de un lado el impulso de la individuación humanista, de otro el intento de unificar un vasto inventario de formas que de algún modo la imprenta vino a podar ${ }^{6}$, en lo que a la transmisión se refiere, reconfigurando -digamos que como apenas texto- un conglomerado medial de extraordinaria riqueza y variabilidad diatópica y cultural: oralidad, voz, gestualidad, hexis corporal, escenificación, visualidad, baile, música, coordenadas momento/lugar en su oportunidad y adecuación ético-patéticas (kairos), interacción entre los enunciador(es) y los enunciatario(s), la performatividad/efectividad de esa presencia en un espacio social compartido y otros procedimientos informativos, comunicativos y en general de producción de semiosis.

2. La expresividad supuestamente no mediada del sujeto y de su particularidad ideal (Fichte, Hegel) supuso la culminación romántica de la equiparación entre poesía y lírica y la postulación de una canonicidad persistente que mantiene vigencia casi plena a día de hoy, según demuestran los correlatos historiográfico-literario y escolar del canon, entre otros.

3. La doxa romántica se fundamentó en una ontología poética específica con apoyos declarados en el autotelismo y la autonomía del discurso, la verdad, la dignidad y el lenguaje diferenciado, dando lugar a lo que podría considerarse una teoría elocutivo-sentimental del lenguaje poético.

4. Advertidos contra toda simplificación dicotómica o no relacional, cabe interpretar que la poesía no lírica contemporánea prescinde en general de la centralidad de un sujeto enunciador marcado por características como las siguientes (legibles consiguientemente como marcas de liricidad): ajuste a una

\footnotetext{
${ }^{5}$ Puede consultarse el índice en http://grupoalea.files.wordpress.com/2011/08/casas-bollig-resistance and emancipation-contents1.pdf [última consulta, 23-11-2011].

${ }^{6}$ Naturalmente, a la vez que abría muchas otras vías.
} 
conciencia individual coherente que propicia la introspección vivencial y constituye una subjetividad declarada, resultante de lo que José Guilherme Merquior llamaba «una mímesis interna»; subordinación de toda diégesis a la presentidad extra-histórica; asimilación de las pautas discursivas de la sublimidad, la no-ficcionalidad, la privacidad, la intensidad, la densidad, la homoglosia y la brevedad (poema = soliloquio transcrito); $\mathrm{y}$, en fin, determinación de un pacto de lectura correlativo y homológico con todo lo anterior.

5. Desconozco que exista una teorización marco o una conceptualización que a día de hoy refieran, con la flexibilidad que se entienda necesaria y sin necesidad de afanes salidos de madre, el conjunto de prácticas poéticas no líricas actuantes en el espacio público. Ir hacia esa teorización, que ha de ser diatópica y crítica, es tarea tan justificada como perentoria ${ }^{7}$. Hacer ese camino excede con toda probabilidad el tránsito disciplinario más corriente. Se necesita, más que una transdisciplinariedad al uso, la colaboración entre analistas y teóricos de saberes humanísticos, sociales y empíricos diversos; pero, ante todo, lo preciso es una reactivación del trabajo de traducción entre disciplinas, la inteligibilidad mutua entre saberes que no aspiren a homologar ni a canibalizar otras formas de conocimiento-emancipación, en el sentido que otorga a estas expresiones el sociólogo Boaventura de Sousa Santos (2002).

6. Tres conceptos procedentes de marcos epistemológicos y disciplinarios diferentes me han parecido eficaces para hablar de las nuevas prácticas poéticas, y en particular para la que hemos acordado denominar poesía no lírica, o ya para todo análisis del lugar cultural y/o del lugar político del poema $^{8}$, lo cual implica a su vez un rumbo posible para la tarea teórico-crítica dirigida a esta clase de producción ${ }^{9}$. Los conceptos son los de subjetivación

\footnotetext{
${ }^{7}$ Un ejemplo digno de atención, con nutrida participación de poetas y de especialistas en diferentes áreas por cierto, es el libro coordinado por Marjorie Perloff y Craig Dworkin The Sound of Poetry / The Poetry of Sound (2009).

${ }^{8}$ He podido ampliar estas ideas, analizando a la vez su rendimiento crítico, en algunas publicaciones recientes: "Antagonism and Subjectification in the Poem of Resistance" (Gräbner y Wood, 2010: 71-81; accesible en http://www.cosmosandhistory.org/index.php/journal/article/view/202/311 [última consulta, 23-11-2011]), "Teoría crítica y discurso de resistencia: lo político en la enunciación poética" (Casas y Bollig, 2011: 53-72), "Non-Lyric Poetry in the Current Genre System" (Baltrusch y Lourido, 2012) y "La poesía no lírica: enunciación y discursividad poéticas en el nuevo espacio público" (Casas, 2012).

${ }^{9}$ Resulta innegable la referencialidad foucaltiana (no exclusiva) de los tres conceptos que se detallarán a continuación, por lo que será provechoso tener presente la función de la crítica tal como el propio Foucault la entendió, en correlato con la Aufklärung (Foucault, 1990). Al respecto, es recomendable recordar la discusión que Judith Butler concretó a propósito de esa posición con referencia asimismo a las propias de Kant, Adorno, Williams y Habermas. En aquella es capital el concepto de desujeción (désassujettissement), que Foucault delimitó como la función esencial de la crítica ante la política de la verdad: «on voit que le foyer de la critique, c'est essentiellement le faisceau de rapports que noue l'un à l'autre, ou l'un aux deux autres, le pouvoir, la vérité et le sujet. [...] la critique, c'est le mouvement par lequel le sujet se donne le droit d'interroger la vérité sur ses effets de pouvoir et le pouvoir sur ses
} 
(Rancière), entendido como la producción de una capacidad de enunciación antes inexistente en un determinado campo de experiencia, mediante la cual queda definido un nuevo espacio de sujeto y se funda una realidad nueva que en términos estéticos y políticos se ligan al disenso o desacuerdo; acontecimiento (Deleuze, Foucault, Badiou), otra vez con la marca del cambio y con las notas de alteridad y ruptura no neutralizables, presentes ya en la vieja cita de Rimbaud - «La poésie ne rythmera plus l'action, elle sera en avant»- con la que René Char abría en 1966 sus "Réponses interrogatives à une question de Martin Heidegger" y postulaba una comprensión de la poesía como acción antes de la acción ${ }^{10}$; y poesíalarte para lo político (Mouffe, Bal), con centralidad para la idea de agonismo político en tanto superación de la pospolítica y con un cuestionamiento de los paradigmas mimético y expresivo que comienza por reafirmar el carácter discursivo y por ello no trascendente del sujeto.

El conjunto de diez artículos que integran este dosier ha sido pensado, lo mismo que otras publicaciones de los grupos de trabajo mencionados, sobre la base de sumar desarrollos propios con otros que corresponden a núcleos de investigadores que de algún modo convergen -como es lógico, desde presupuestos y referentes específicoscon el programa de análisis y con los objetivos que se han descrito. Tal convergencia no es completa ni significa de modo necesario que exista una asimilación en uno u otro sentido. Ni siquiera debiera darse por supuesta la congruencia metodológica. Lo perceptible y fácilmente constatable es la existencia de analogías heurísticas y también una distancia con la crítica acomodaticia; en fin, con lo que Boaventura Santos ha

discours de vérité; eh bien! la critique, cela sera l'art de l'inservitude volontaire, celui de l'indocilité réfléchie. La critique aurait essentiellement pour fonction le désassujettissement dans le jeu de ce que'on pourrait appeler, d'un mot, la politique de la vérité» (Foucault, 1990: 39). Los ensayos de Foucault y de Butler figuran, éste tras aquél (traducido al inglés), en la compilación The Political (Ingram, 2002: 191211 y 212-226). Una traducción al castellano del segundo, debida a Marcelo Expósito y Joaquín Barriendos con el título “¿Qué es la crítica? Un ensayo sobre la virtud de Foucault”, puede verse en http://eipcp.net/transversal/0806/butler/es [última consulta, 23-11-2011]. Del texto de Foucault "Qu'estce que la critique? (Critique et Aufklärung)" es accesible asimismo una traducción al castellano. Figura en el repositorio de la Universidad de los Andes (Mérida), http://www.saber.ula.ve/handle/123456789/ 15896 [última consulta, 23-11-2011], y se debe a Jorge Dávila.

${ }^{10}$ En su comentario-epílogo a la traducción gallega de las "Réponses" de Char, escribe Carlos Lema (2011: 23): «Así, a linguaxe non substituiría a presenza, non sería re-presentativa, senón que deixaría traza dunha ausencia. A linguaxe non sería a realidade e, daquela, xa non actuaría, xa non sería 'operativa' nin 'meditativa' senón que meditación e acción devirían indiscernibles. Aceptaríase dese xeito que o pensar especulativo modifica o real mentres que a predicación soamente o reproduce». 
descrito como razón indolente, pero sin excluir -hay que reiterarlo- la discrepancia, incluso ya en el planteamiento de partida. En cualquier caso, el propio sociólogo portugués, como otros colegas asimismo atentos a los operativos de trabajo de las ciencias sociales en América Latina, ha defendido que ante esa actitud de indolencia cabe reaccionar desde la investigación-acción y en especial desde lo que, yendo un paso más allá, llama ecología de saberes, promotora de un diálogo entre los saberes académicos y los no académicos, también mediante la puesta en común de lo que conoce el analista y lo que hace (y conoce) el sujeto o la comunidad estudiados. Esto es de inmediata aplicación a nuestro campo de intereses. Representaría de entrada franquear la interacción entre el discurso teórico-crítico y las plurales prácticas poéticas que ocupan un lugar en el espacio público actual; sin abstraerse, sobra señalarlo, de aquellas que emergen en las periferias o las semiperiferias sociales o geoculturales del sistema/campo.

Una característica común a los artículos que ahora presento es su interés por trabajar en un territorio teórico-crítico. En algunos predomina la primera vertiente; en otros, quizás la mayoría, es la mirada crítica la que se ha considerado oportuno dimensionar con cierta amplitud, si bien con un propósito evidente de representatividad, de caso en el que se entrecruzan trayectos múltiples que trascienden la descripción de prácticas y de poéticas únicas. Por otra parte, aunque ese ejercicio crítico casi nunca se ha conformado por exclusión de otros marcos lingüístico-culturales, lo evidente es que se ha priorizado una atención a las literaturas ibéricas y latinoamericanas.

El dosier lo abre un trabajo de Juan Carlos Rodríguez referido a las condiciones culturales y políticas de nuestra subjetividad en el mundo actual, y en concreto al seguimiento de lo que estudia como "efecto Foucault" en su deriva neoliberal, valedor en suma del dogma posmoderno esencial, el del yo libre, y, en otro plano, también de una buena parte de los desarrollos contemporáneos de la teoría literaria. Entre las manifestaciones consolidadas de este efecto destaca el autor el constructivismo cultural y la autorreferencialidad discursiva, al tiempo que detalla las inflexiones principales del pensamiento de Foucault y de sus epígonos norteamericanos (con las correspondientes réplicas: en especial, las debidas a Rorty). El punto de llegada no es otro que el cuestionamiento -desde Marx, desde Spinoza, desde Freud- de las formulaciones más extendidas sobre la subjetividad lírica (impuesta) y la subjetivación/objetivación no lírica, esta última proyectada en tanto respuesta aún no liberada de la creencia en el yo nacido libre. La necesidad de re-trazar el problema tendría que apoyarse para Rodríguez en la substitución de esta creencia por la que la impugna, pues no nacemos ni libres ni iguales. 
Rosa Maria Martelo estudia en su artículo los rumbos de la poesía portuguesa contemporánea a partir del momento en el que Carlos de Oliveira publicó Cantata (1960) y rompió con algunas de las inercias de la poética neorrealista, incluido su pacto de lectura implícito, y con la propia conceptualización del compromiso intelectual en perspectiva marxista. El cambio no fue exclusivo del poeta mencionado. Se produjo de hecho todo un movimiento en simultaneidad, participado en diversa medida por Gastão Cruz, Luiza Neto Jorge, Herberto Helder, Ruy Belo, Sophia de Mello Breyner Andresen, Eugénio de Andrade, Mário Cesariny y varios otros poetas de primera línea, que Martelo formula como el paso de un programa asentado en la resistencia en (o desde) la poesía a otro que lo fue de resistencia de la poesía. El cambio habría afectado además la hechura enunciativa del poema, ya desde el abandono de la función testimonial y vicaria del sujeto poético, anteriormente presto a hablar en el lugar de quienes sufrían la historia; pero sobre todo rehabilitó para el debate el principio de autonomía artístico-literaria, que la autora contextualiza con las posiciones de Adorno, Deleuze y Derrida, al tiempo que amplía la atención a poéticas posteriores, de ahora mismo incluso (José Miguel Silva, Adília Lopes...), en las que es constatable otra comprensión de la autonomía poética.

Sin abandonar esta última referencia, Jordi Claramonte Arrufat propone una tipología de las intervenciones artísticas autodeclaradas políticas y pensadas para su despliegue en espacios públicos. Distingue así en su ensayo entre las poéticas de la denuncia, las poéticas colaborativas y las poéticas relacionales. Las primeras se caracterizarían por una marca todavía fuerte de la función autorial/institucional y por desinteresarse en profundizar en el vínculo con la comunidad afectada por el conflicto político referido (Claramonte menciona a Haacke como representante de esta línea). Las poéticas colaborativas estarían marcadas por una menor institucionalización, lo cual a menudo repercute en la obra en tanto resultado artístico y restringe también los espacios de intervención, aunque suele potenciar la creación o el refuerzo de redes sociales de apoyo. Las poéticas relacionales, en fin, tratarían de acelerar el proceso redefinidor de lo cultural y lo artístico, si bien perderían efectividad comparadas con las de denuncia y agencialidad social transformadora confrontadas con las colaborativas. Con apoyo en Lukács, Foucault y otros teóricos, el autor encuentra alternativas en una estética modal en la que la autonomía estética y la funcionalidad social dejan de verse como elementos antitéticos. Define así la intervención poética en el espacio público como un proceso por el que un grupo construye las condiciones para un ámbito de libertad concreta liberando con su acción un nuevo modo de relación.

Claude Le Bigot estudia en su ensayo la incorporación de una cotidianidad urbana de corte neorrealista en la poesía española de los últimos treinta años, con mención 
especial de la producción poética de Luis García Montero, Fernando Beltrán, Jorge Riechmann y Roger Wolfe. Se interesa en especial por las tensiones que el poema llega a poder documentar y discursivizar en torno a la relación entre el individuo y la colectividad, acaso ante un horizonte que a propósito del último de los poetas citados se nombra como construcción de un ethos democrático. De lo que se trataría por tanto es de entender y concretar la actitud realista en una clase de poesía en la que la experiencia y la sentimentalidad han definido todo un campo de juego. Le Bigot, de acuerdo con García Montero, analiza en consecuencia la historicización de la subjetividad en tanto forma de superar la dicotomía público/privado en el campo poético y muestra el rendimiento que para ello ofrecen las micro-historias, la figuración, la ironía, el humor, la parodia, la iconoclasia, la complicidad y otros elementos repertoriales de la estética estudiada.

Justamente a la obra de Jorge Riechmann ha dedicado su artículo Laura Scarano. Sigue para ello un rastro en el que la resistencia social, la militancia ecologista, el desconsuelo... son piezas de una cartografía a todas luces inmersa en las condiciones económicas y políticas del capitalismo cultural descrito por Jameson. Así, Scarano procede en su lectura de los poemas-crónica de Riechmann, en especial -por su valor emblemático- los de El día que dejé de leer El País (1997), a una descodificación de los procedimientos inventivos, dispositivos y elocutivos de unos textos-collage en los que se descubre una ventriloquía que en buena medida reduce la escala moral de todo discurso, de toda posibilidad de discurso, ante el poder ubicuo de la globalización neoliberal, con su voz sistémica aparentemente superpuesta a toda reacción liberadora. Claro que este operativo estaría destinado en sentido perlocucionario por el poeta a una movilización de las actitudes cívicas, a una emancipación en suma que lograra abrir el diámetro del espacio de los posibles sociales e ideológicos sin que ello silenciase una querencia por lo íntimo o un interés por sondar una subjetividad nueva, en Riechmann configurada bajo el signo de lo mixto.

Isaac Lourido Hermida presenta algunas características del campo cultural gallego y menciona las razones sistémicas, políticas y simbólicas que explican la centralidad histórica de la poesía, algo no infrecuente en sistemas emergentes. El artículo fija la atención en tres planos. El primero es la presencia de la poesía oral en el espacio público gallego merced a la proliferación de diversas formas de recitales, festivales, intervenciones de colectivos, parateatralización/escenificación y en general la exploración de las posibilidades de la poesía en voz alta. El segundo viene dado por la relación entre poesía y música a través de las trayectorias de cantautores, grupos y colectivos, con una amplia fenomenología de registros entre la canción melódica y el hip-hop, o entre el jazz, el reggae y el Movimiento Bravú. El tercero de los planos 
consiste en un análisis de las bases ideológicas, repertoriales e institucionales de tres proyectos específicos de diversa naturaleza poético-musical: Rosalía 21, coordinado por el poeta e investigador Anxo Angueira, en colaboración con el pianista de jazz Abe Rábade y la cantante Guadi Galego, como una reivindicación en clave nacional, feminista y de clase de la figura de Rosalía de Castro; Labregos do tempo dos Sputniks (O Leo i Arremecághona, García y Silverio Outeiro), con nítida recepción de la poética social de Celso Emilio Ferreiro y una reinscripción de su actitud cívico-discursiva ampliada a la actividad de las redes sociales; y Fanny + Alexander, con un repertorio más fácilmente discernible y homologable en términos de internacionalización por su amilación del pop electrónico, en todo caso nutrido por letras de una notable heterogeneidad en su filiación estética.

El séptimo artículo corresponde a la autoría de Susana Romano Sued, quien expone su concepción de la expoesía y la refiere, desde un prisma ético y político, al ámbito argentino a partir de los pasados años 80, pero con antecedentes en el neobarroco, el situacionismo y la poesía concreta. Expoesía sería así el nombre no totalizante dado una serie amplia de prácticas y experiencias poéticas de tipo experimental marcadas por la intermedialidad y la multidimensionalidad, que consecuentemente exigen otra clase de recepción, algo que la autora introduce acudiendo al pensamiento de Benjamin. Señala además Romano Sued que el rótulo de lo expoético se instaura con objeto de concentrar la atención sobre la necesaria superación de las restricciones de un cuerpo categorial hoy obsoleto si se aspira a su utilización para dar cuenta de fenómenos que sin duda lo exceden. Entre ellos, por ejemplo, la producción de grupos expoéticos intervinientes en distintas ciudades del país, como el PARA de Misiones, los Iconoclasistas de Buenos Aires y el ProtoCopyleft L, de Córdoba, o la revista de artes visuales ramona $(2000-2010)^{11}$.

Cornelia Gräbner aplica en su ensayo algunas de las herramientas críticas a las que hicimos alusión a propósito del trabajo de Mieke Bal y ASCA, principalmente la de concepto-metáfora, para exponer una lectura de la novela corta de Antonio Skármeta El cartero de Neruda -propiamente, Ardiente paciencia (1985) título original y eco del del poema de Rimbaud "Adieu”, de Une saison en enfer ${ }^{12}$ - como teorización de la relación entre poesía y política, la primera como elemento constitutivo de la segunda. Todo ello, como es lógico, ante el telón de fondo del golpe de estado de septiembre de 1973 contra la democracia y el gobierno de Salvador Allende. Tal teorización tiene presentes asimismo conocidas consideraciones de Roland Barthes y Hazard Adams sobre el escándalo total del lenguaje y la ofensa de la poesía. Gräbner entiende estos y otros

\footnotetext{
${ }^{11}$ Sus contenidos son ahora accesibles en http://www.ramona.org.ar [última consulta, 23-11-2011].

12 «Et à l'aurore, armés d’une ardente patience, nous entrerons aux splendides villes».
} 
conceptos-metáfora como escollos que presentan un desafío de orden moral y político a quien lee, de modo que su artículo supone a la vez una indagación sobre las condiciones culturales y políticas de lectura de la poesía, sobre la asimilación popular y académica de su función comunal, cohesionadora y dignificadora, pero también de su capacidad para generar una forma de conocimiento que como los propios conceptos-metáfora nos pueda decir algo sobre las más complejas relaciones humanas, sobre la verdad histórica y sobre los proyectos de emancipación social y política.

El artículo de Ben Bollig introduce una dimensión por completo necesaria para nuestro foco de atención. Tiene que ver con el sujeto subalterno y su modo de entender el espacio cultural al que emigra, de modo que en algún sentido se comprometa aquel individuo o aquel grupo en una tarea vital de activismo y comprensión intercultural y de traducción entre prácticas sociales y culturales de diversa procedencia, sumadas por supuesto las poéticas y las musicales, lo mismo que determinadas disposiciones de tipo religioso, sexual, festivo, etc. Bollig estudia la trayectoria del narrador y poeta argentino Washington Cucurto, conocido también por haber promovido la editora comunitaria Eloísa Cartonera, que cobró impulso a raíz del colapso económico nacional de 2001 y que sirvió después como modelo de economía solidaria a otros proyectos cartoneros en toda América Latina. Pero en el artículo se reclama una atención específica al papel de activista cultural de Cucurto y a su producción literaria, en la que la inmigración, la marginación social y la diversidad/comprensión cultural ocupan un primerísimo plano, casi siempre como correlatos temáticos de la violencia y del impulso sexual. El autor defiende la existencia en este plano de una homología entre la economía del usufructo y una estética del "robo discursivo", que documenta con un análisis de una de las obras poéticas de Cucurto, La máquina de hacer paraguayitos (1999), una especie de reportaje poético sobre la inmigración dominicana en Buenos Aires con protagonismo particular para las mujeres, o en general sobre la diáspora dominicana en los años de gobierno de Trujillo y sobre todo de Balaguer, que se vehicula además en sentido comparado con otras dos obras volcadas en el mismo referente histórico, La fiesta del Chivo (2000), de Mario Vargas Llosa, y The Brief Wondrous Life of Oscar Wao (2008), de Junot Díaz.

El artículo con el que se cierra el dosier corresponde a Ana Chouciño Fernández y atiende otra parcela ineludible que se ha entendido conveniente representar. En concreto la de la canción popular, en este caso por referencia específica a la guaracha cubana (con antecedentes en el teatro bufo del siglo XIX), a su circulación social y a los procedimientos de hibridación que dan paso a la incorporación del anecdotario cotidiano y del choteo. Todo ello con una funcionalidad cultural que podría explicarse como distensión pública de una conflictividad privada, si bien la guaracha otorga 
también cabida a matizadas tomas de posición sobre determinados asuntos colectivos y políticos, sobre todo los tocantes al abuso de autoridad. De modo que asistiríamos a una forma de representación de determinados usos conversacionales, no necesariamente relevantes como registro de desigualdades sociales pero sí -y mucho- en el plano de la discursivización y la caracterización del género, como el estudio deja en claro mediante la cita de ejemplos bien explícitos, extensibles a toda clase de clichés sexuales y estereotipos étnicos y/o conductuales, a menudo con refuerzo último de la moral patriarcal criolla. En la guaracha, que suma a la palabra la danza además de la música (güiro, tres, maracas), se produjo otro fenómeno de interés destacado por Chouciño: la conquista de la calle, la expansión desde el escenario de los pequeños teatros al espacio urbano común, donde se mantiene además la espectacularidad paraescénica asociada a una indumentaria de condición vistosa y carnavalesca.

Concluyo indicando que este dosier se asocia con el proyecto de investigación $E l$ discurso no lírico en la poesía contemporánea: Espacios, sujetos, hibridación enunciativa, medialidad (MICINN, FFI2009-12746). Permítaseme declarar también aquí mi cordial agradecimiento a la totalidad de los colaboradores por el valor y el rigor de sus propuestas, que a buen seguro mantendrán activos en este y otros foros los debates abiertos. Mi sincera gratitud asimismo al director y los subdirectores de Tropelías por su confianza y generosidad en el arranque de esta nueva fase de la revista.

\section{Referencias bibliográficas}

BAL, M. (2009): Conceptos viajeros en las humanidades. Una guía de viaje. Trad. Y. Hernández Velázquez. Murcia: CENDEAC. Ed. original: Travelling Concepts in the Humanities: A Rough Guide. Toronto, University of Toronto Press, 2002.

BALTRUSCH, B. - LOURIDO, I. eds. (2012): Non-lyric Discourse in Contemporary Poetry. Múnich, Martin Meidenbauer, en prensa.

CASAS, A. (2012): "La poesía no lírica: enunciación y discursividad poéticas en el nuevo espacio público”, en D. SÁNCHEZ-MESA et al. eds., Actas del I Congreso Internacional de la Asociación Española de Teoría de la Literatura. Granada, 2628 de enero de 2011, en prensa.

CASAS, A. - BOLLIG, B. eds. (2011): Resistance and Emancipation: Cultural and Poetic Practices. Oxford y Berna, Peter Lang, serie "Hispanic Studies. Culture and Ideas". 
GRÄBNER, C. - WOOD, D. M. J. eds. (2010): The Poetics of Resistance, número monográfico de Cosmos and History. The Journal of Natural and Social Philosophy, 6/2 http://www.cosmosandhistory.org/index.php/journal/issue/view/10 [última consulta, 30-11-2011].

GRÄBNER, C. - CASAS, A. eds. (2011): Performing Poetry: Body, Place and Rhythm in the Poetry Performance. Nueva York y Ámsterdam, Rodopi, serie "Thamyris/Intersecting".

FOUCAULT, M. (1990): “Qu'est-ce que la critique? (Critique et Aufklärung)”, Bulletin de la Société Française de Philosophie, 84/2, pp. 35-63. Transcripción de la conferencia dictada el 27 de mayo de 1978, seguida de debate.

INGRAM, D. ed. (2002): The Political. Londres, Blackwell.

LEMA, C. (2011): Poesía, linguaxe e acción (con René Char). Santiago de Compostela: Amastra-n-gallar.

PERLOFF, M. - DWORKIN, C. eds. (2009): The Sound of Poetry / The Poetry of Sound. Chicago y Londres: The University of Chicago Press.

POLlOCK, G. ed. (2007): Conceptual Odysseys: Passages to Cultural Analysis. Introducción de M. Bal. Londres y Nueva York, I. B. Tauris.

SANTOS, B. S. (2002): Towards a New Legal Common Sense: Law, Globalization, and Emancipation. Londres, Butterworths, $2^{\mathrm{a}}$ ed. 